\title{
SAMATURU: MENSTIMULASI SPIRIT KOLABORASI GURU UNTUK MELAKSANAKAN LESSON STUDY
}

\author{
Nasir $^{1}$, Mujiati $^{2}$, Asrul $^{3}$ \\ Universitas Muhammadiyah Kendari, dhion_zir@yahoo.com
}

\begin{abstract}
ABSTRAK
Berawal dari fakta guru-guru yang mengisolasi diri untuk berinterkasi dengan guru lain; tidak mau berbagi (sharing pengalaman) dan enggan bekerja sama menyelesaikan masalah pembelajaran, maka penelitian ini dilakukan untuk memahami nilai-nilai budaya Samaturu sehingga semangat kolaborasi guru memulai lesson study bisa tumbuh. Dengan menggunakan teori Dick \& Carey, pendekatan semi research and development dipilih untuk memformulasi Model hipotetik Lesson Study berdasarkan Spirit Samaturu. Peneliti menggunakan study pustaka dan study lapangan; melakukan wawancara kepada beberapa informan yang terdiri dari tokoh masyarakat lokal, dan administrator sekolah. Data yang dikumpukan kemudian dianalisa secara sejajar; membandingkan data lapangan dan penelitian-penelitian terdahulu. Penelitian ini menyimpulkan jika budaya Samaturu mengandung nilai semangat kerjasama, tolong menolong, ikhlas dan lain-lain. Mengekstraksi nilai Samaturu akan bermanfaat untuk menumbuhkan semangat kolaborasi guruguru. Samaturu mengajarkan kepada guru-guru agar dapat berkontribusi pada kegiatan lesson study menurut kemampuan masing-masing; berdasarkan keikhlasan dan suka rela, tanpa pamrih, dan meyakini jika kerja atau usaha tersebut bermanfaat bagi kepentingan bersama.
\end{abstract}

Kata Kunci: Kearifan Lokal, Lesson Study; dan Samaturu

\begin{abstract}
Starting from the fact that much teacher isolate themselves to interact with other teachers; do not want to share (experience sharing) and are reluctant to work together to solve learning problems, then this research was conducted to understand the cultural values of Samaturu since the spirit of collaboration of teachers starting lesson study can grow. Using Dick \& Carey's theory, a semi research and development approach was chosen to formulate the Lesson Study hypothetical Model based on Spirit Samaturu. Researcher used study of literature and field study; conducted interviews with several informants consisting of local community leaders, and school administrators. The collected data were then analyzed in parallel; comparing field data and previous studies. This study concludes that the culture of Samaturu contains the value of the spirit of cooperation, habit of helping, sincerity and others. Extracting Samaturu values will be beneficial to foster a spirit of collaboration among teachers. Samaturu influences teachers to be able to contribute to lesson study activities according to their abilities; based on sincerity and voluntary, without strings attached, and believes if the work or business is beneficial to the common good.
\end{abstract}

Keywords: Local wisdom, Lesson study, and Samaturu

\section{PENDAHULUAN}

Benang merah lesson study adalah

kolaborasi dan bekerja sama. Disebutkan oleh Ngang\& Sam (2015) bahwa lesson

study adalah model pembinaan 
(pelatihan) profesi pendidik melalui pengkajian pembelajaran secara kolaboratif dan berkelanjutan berdasarkan prinsip-prinsip kolegalitas dan mutual learning sehingga dapat terbangun komunitas belajar. Sedangkan Shelley Friedkin (2005) mendefinisikan lesson study sebagai suatu proses yang melibatkan guru-guru yang bekerja sama untuk merencanakan, mengobservasi, menganalisis, dan memperbaiki pembelajarannya. Selanjutnya Perry $d k k$ (2009); Fernandez \& Yoshida (2012) menjelaskan bahwa lesson study adalah salah satu model pendekatan pengembangan profesi melalui "belajar dari praktek". Selama lesson study, para guru merumuskan tujuan pembelajaran dan pengembangan dalam jangka panjang; secara kolaboratif bekerja pada "penelitian pembelajaran" untuk mencapai tujuan pembelajaran; mengamati, mendokumentasikan dan mendiskusikan respon siswa terhadap pembelajaran; dan meninjau kembali pembelajaran tersebut, serta memperluas pendekatan pembelajaran. Kumpulan definisi di atas menguatkan hipotesa penulis bahwa lesson study harus diawali dengan spirit keingingan guru-guru untuk berkolaborasi dan bekerja sama menyelesaikan masalah-masalah yang terjadi dalam pembelajaran.
Chassels \& Melville (2009) dalam penelitiannya menemukan bahwa guruguru di Jepang berhasil mengubah pendekatan mereka dalam mengajar sains, mulanya "mengajar sebagai pencerita" menjadi "mengajar untuk memahami" melalui pembelajaran dan berbagi selama lesson study. Guru-guru Jepang percaya bahwa waktu yang dihabiskan untuk lesson study akan meningkatkan kualitas pengajaran mereka. Selain itu, mereka percaya bahwa tempat paling efektif untuk meningkatkan pengajaran mereka adalah dalam konteks pelajaran di kelas (Hock \& Sam, 2010). Implementasi lesson study dalam proses pembelajaran sangat membantu meningkatkan siswa untuk belajar. Guru menjadi lebih bersemangat dalam melakukan upaya perbaikan untuk membuat siswa belajar. Hal yang sama terjadi pada siswa, dengan melihat semangat belajar guru memberi dampak positif, di mana siswa lebih aktif di kelas dan berperilaku lebih baik dalam proses pembelajaran (Triyanto, 2016). Meskipun demikian, masih banyak guru yang menolak brekolaborasi dan berinteraksi satu sama lain (Shakenova, 2017). Shakenova menyebut guru-guru yang mengisolasi dari dengan sebutan cellular structured teachers. menurutnya, isolasi mencegah peningkatan kreativitas dan 
instruksi pengajaran. Oleh karena itu, langkah awal sebelum memulai lesson study: merencanakan, mengobservasi, menganalisis, dan memperbaiki pembelajaran, yang pertama harus dilakukan yaitu menumbuhkan semangat kepribadian yang kolaboratif dan sikap terbuka (interaksi) guru.

Utami (2019) menyimpulkan jika karakter dibentuk dari kegiatan-kegiatan kedisiplinan di sekolah. Bleidorn, Kandler, \& Caspi (2014) mempelajari budaya bersama dan kepribadian. Budaya (apapun bentuknya) adalah variabel yang dapat mempengaruhi kepribadian. Kepriabdian setiap individu yang berbeda-beda dibentuk oleh budaya yang mereka percayai (Leung \& Cohen, 2011). Di samping itu, manusia juga dibentuk oleh lingkungan. Budaya mempengaruhi perkembangan kepribadian (Triandis \& Suh, 2002). Budaya ditransmisikan melalui bahasa dan pemodelan perilaku. Bahasa memungkinkan manusia Berkomunikasi, sedangkan pemodelan perilaku lahir ketika hidup pada periode bersejarah yang sama. Setiartin (2016) menyimpulkan jika tradisi atau budaya dapat dijadikan alat atau media pembentukan mental dan kepribadian.

\section{METODE PENELITIAN}

Budaya seperti "Sawer Panganten" yang merupakan tradisi lisan yang yang terdapat di tatar Sunda memiliki nilainilai baik dari sisi ketuhanan, moral, kecerdasan, maupun keilmiahan. Selanjutnya Nasir (2013) menyebutkan jika budaya memberi andil pada penigkatan karakter seseorang. Bahkan dalam artikel publikasinya, dia menyebutkan secara eksplisit budaya lokal dapat menghapus intoleran, mempertebal kepedulian sesama, menumbuhkan sikap tanggung jawab, mempermudah hal yang rumit dilakukan sendiri, meningkatkan solidaritas, menambah kokohnya rasa persatuan dan kesatuan dan mempertinggi ketahanan bersama.

Berdasarkan narasi-narasi di atas, kajian dalam tulisan ini yaitu untuk menemukan tradisi atau budaya lokal yang dapat diekstrakasi sebagai upaya membangun dan menumbuhkan persepsi guru agar bersikap terbuka dan mau berinterkasi, khususnya berkolaborasi degan guru-guru lain melakukan refleksi kegiatan belajar sehingga diperoleh kualitas pembelajaran yang lebih baik dan inovatif.

Penelitian ini menggunakan metodologi penelitian pengembangan (semi research and development). 
Merujuk teori Dick \& Carey (2009) menyebutkan tahapan semi research and development yakni: analisis kebutuhan, desain produk, validasi dan evaluasi, tahap produk akhir, serta diseminasi model. Sesuai dengan target penelitian yaitu model hipotetik lesson study, maka penelitian ini tidak menggunakan semua tahapan dalam penelitian pengembangan. Tahapan lanjutan seperti validasi, evaluasi dan diseminasi akan direncanakan pada penelitian-penelitian berikutnya.

Penelitian diawali dengan study pustaka, kemudian dilanjutkan dengan study lapangan; menelusuri tentang nilainilai yang menjadi dasar hidup masayarakat lokal (Kota Kendari), sehingga terkumpul data yang diperlukan sebagai bahan pengembangan model. Peneliti memilih 5 tokoh masyarakat lokal, beberapa guru dan administrator sekolah untuk diwawancarai. Pewawancara melakukan tanya jawab tatap muka sambil membuat catatatan singkat untuk berjaga-jaga jika perekam mengalami kegagalan fungsi. Catatan lapangan kemudian dianalisis menggunakan model induktif; cycling code, patterning code, jotting, memoing, assertion dan proposition development (Miles, Huberman, \& Saldana: 2014). Selanjutnya, data di analisa dengan tahapan-tahapan memahami, mensintesis, perbandingan teori, dan selanjutnya ditarik kesimpulan.

\section{HASIL DAN PEMBAHASAN}

A. Filosofi Samaturu sebagai Tradisi Lokal

Samaturu dipilih sebagai budaya lokal yang menumbuhkan kepribadian suka berbagi dan bekerja sama karena samaturu adalah tradisi yang berarti tolong menolong dan saling membantu. Samaturu ditemui ketika masyarakat menghadapi permasalahan, baik sosial maupun pemerintahan seperti: upacara adat, pesta pernikahan, kematian maupun dalam melaksanakan peran dan fungsinya sebagai warga negara, selalu bersatu, bekerjasama, saling tolong menolong dan bantu-membantu. Samaturu merupakan budaya yang telah ada dan tumbuh di kehidupan sosial masyarakat Tolaki sebagai warisan budaya turun-temurun. Nilai Samaturu sebenarnya mengandung semangat yang diwujudkan dalam bentuk perilaku atau tindakan individu yang dilakukan tanpa mengharap balasan untuk melakukan sesuatu secara bersamasama demi kepentingan bersama atau individu tertentu. Perkenalan tentang Samaturu sebagai tradisi masyarakat Tolaki sebagaimana dikutip dari 
penjelasan-penjelasan para informan di bawah ini: diupayakan dan dilaksanakan oleh para orang tua yang saat ada" (RTM2)

"Samaturu merupakkan bentuk kerja-sama masyarakat untuk mencapai suatu hasil positif secara mufakat dan musyawarah bersama. Samaturu muncul atas asas kesadaran dan semangat untuk mengerjakan serta menanggung akibat secara bersama-sama, serentak dan beramai-ramai, tanpa memikirkan dan mengutamakan keuntungan pribadi, melainkan selalu untuk kepentingan bersama" (RTM3)

"Nilai Samaturu itu harusnya dimiliki semua unsur atau lapisan masyarakat Tolaki. Karena dengan adanya kesadaran setiap elemen tersebut, segala sesuatu yang akan dikerjakan dapat lebih mudah dan cepat diselesaikan. Bukan itu saja, adanya kesadaran menerapkan Samaturu maka hubungan persaudaraan atau silaturahmi akan semakin erat" (RTM4)

Sebagaimana petikan-petikan wawancara di atas, telah dipaparkan 
bahwa samaturu memiliki nilai-nilai yang menjadikan kebiasaan-kebiasaan tersebut menjadi budaya yang sangat baik untuk dipelihara. Samaturu dapat menumbuhkan sikap sukarela, tolongmenolong, kebersamaan, dan kekeluargaan antar sesama anggota masyarakat. Masyarakat yang mau melakukan gotong royong dan samaturu akan lebih peduli pada orang-orang yang ada di sekitarnya.

Pertanyaan menggelitik pada telinga kita saat ini, Sudah benar-benar habiskah budaya Samaturu di masyarakat saat ini? Bagaimanakah budaya tersebut bisa dipertahankan di era globalisasi yang merangsek semakin kencang saat ini? Semua komponen harus bertanggung jawab mentransmisi Samaturu agar menjadi karakter yang tetap ada bagi generasi berikutnya, karena sesungguhnya budaya samaturu merupakan kekuatan besar budaya masyarakat yang perlu dikembangkan terus.

Perubahan-perubahan yang melanda bangsa ini telah banyak mengikis sifat dasar kebangsaan dan berubah menjadi nilai lain yang merupakan lawan dari semangat samaturu, yakni indvidualisme. Terdapat kecenderungan-kecenderungan yang tak dapat ditolak, bahwa individualisme, telah menjadi alternatif dari sistem nilai yang gejalanya terus menguat pada masyarakat. Para informan bersepakat bahwa solusi untuk membuat Samaturu agar menjadi karakter yang tetap dan terus ada.

"Rasa Samaturu dapat distimulasi dan ditumbuhkan lagi mulai dari sistem pendidikan. Dari pendidikan dimulai untuk diajarkan seberapa pentingnya Samaturu. Dengan penanaman dan pengenalan nilai Samaturu sebagai nilai pokok akan membawa ke arah pemahaman konsep dan pengertian manfaat dari Samaturu itu sendiri, sehingga Samaturu menjadi nilai luhur yang terus dijaga dan diturunkan untuk generasi seterusnya" (RTM5)

B. Adaptasi Samaturu ke dalam Implementasi Lesson Study

Samaturu berisi semangat bekerja bersama-sama dan bersifat suka rela menjadikan kegiatan yang dikerjakan dapat berjalan dengan lancar, mudah dan ringan. Demikian halnya lesson study, terdapat prinsip atau asas yang serupa seperti yang terkandung dalam spirit Samaturu yang perlu dipegang sebagai landasan bagi guru-guru. Lesson study 
merupakan model pembinaan profesi pendidikan melalui pengkajian pembelajaran secara kolaboratif dan berkelanjutan berdasarkan prinsip-prinsip kolegialitas dan mutual learning untuk membangun komunitas belajar. Pertanyaan selanjutnya bagaimana menumbuhkan semangat kolaborasi guru agar mau saling langsung bertukar pikiran dan saling memberi masukan? Narasi-narasi selanjutnya adalah deskripsi hasil wawancara peneliti kepada para informan berhubungan dengan adaptasi nilai Samaturu untuk menumbuhkan semangat kolaborasi. Budaya Samaturu sesungguhnya adalah suatu nilai. Sebagai suatu nilai, Samaturu akan bisa diamati setelah diwujudkan dalam aspek tingkah laku. Misalnya, ada orang-orang yang bersama-sama mengerjakan sesuatu dengan tujuan tertentu yang merupakan kepentingan bersama atau dalam konteks refleksi hasil proses belajar, guru bekerjasama untuk menemukan solusi memperbaiki kualitas pembelajaran. Pemaknaan hasil wawancara kepada guru-guru di sekolah membenarkan pernyataan di atas

"Budaya Samaturu mengajarkan kepada kami bahwa setiap partisipan dalam lesson study berkontribusi menurut kemampuan masing-masing, berdasarkan keikhlasan dan suka rela, tanpa pamrih (tanpa harapan balas jasa), dan meyakini jika kerja atau usaha tersebut bermanfaat bagi kepentingan bersama" (Gr dan AS)

\section{Pembahasan Hasil Penelitian}

Sub ini mengelobari temuan-temuan lapangan dengan teori-teori yang relevan. Temuan tentang persepsi para informan di lapangan terkait dengan Samaturu dan adaptasinya dalam pelaksanaan lesson study dikaji dengan menyandingkannya dengan kutipan-kutipan teori dari para pakar.

Paragraph selanjutnya peneliti akan fokus pada pembahasan hasil penelitian sebagaimana rangkuman penelitian di atas. Nasir (2013) mengilustrasikan jika norma atau nilai sosial-budaya merupakan aspek yang terintegrasi dalam proses pendidikan. Artinya, mengadaptasi spirit tradisi Gotong royong dan Samaturu merupakan bagian dari proses pendidikan. Samaturu melahirkan kesadaran dan semangat untuk kebersamaan. Hal tersebut juga dikarenakan di dalam gotong royong terkandung makna collective action to struggle, self governing, common goal, dan sovereignity. 
Pada konteks lesson study, kesadaran dari guru untuk bersikap bijaksana dalam mengatasi permasalahan pembelajaran sangat dibutuhkan. Oleh karena itu, guru perlu melakukan refleksi setelah melakukan pembelajaran di kelas. Sedangkan semangat kebersamaan diperlukan karena permasalahan lesson study harus digali atau didiagnosis secara kolaboratif dan sistematis oleh guru dari masalah yang nyata dihadapi guru dan/atau siswa di sekolah. Bekerja dalam kelompok kecil, para guru berkolaborasi satu sama lain, bertemu untuk mendiskusikan tujuan pembelajaran, merencanakan pelajaran kelas aktual atau disebut "research lesson", mengamati bagaimana gagasan mereka bekerja dalam pelajaran langsung dengan peserta didik, dan kemudian melaporkan hasilnya sehingga guru lain bisa memanfaatkannya (Takahashi \& McDougal, 2016).

Refleksi diri ini penting dilakukan oleh guru karena dengan melakukan hal tersebut, guru akan bisa melakukan perbaikan dalam pelaksanaan tugas. Logikanya, guru akan jujur ketika melakukan refleksi, karena memang tidak ada yang mengawasi. Bagian terpenting dari pembahasan tentang refleksi adalah guru mampu menentukan mengapa pelajaran tidak memuaskan (aktivitas atau materi pelajaran yang tidak tepat, langkah-langkah yang lemah, atau pengelompokan siswa yang tidak tepat) sehingga dapat diperbaiki pada waktu mendatang.

Kolaborasi ketika guru melakukan lesson study diperlukan karena diharapkan akan lebih banyak masukan perbaikan yang secara tidak langsung akan dapat meningkatkan mutu pembelajaran. Sebagaimana pendapat Lewis (2002a), dan Friedkin (2005) bahwa lesson study memberikan ruang bagi guru mengidentifikasi masalahmasalah pembelajaran, merencakan solusi rencana perbaikan pembelajaran, mengimplementikan rencana perbaikan tersebut, dan mengevaluasi serta merevisi pembelajarannya.

\section{Model hipotetik lesson study berdasarkan kearifan lokal}

Pernahkah guru saat mengajar didampingi guru lain? Pernahkah guru merencanakan pengelolaan kelas secara rinci dan detail kemudian hasilnya dievaluasi bersama teman sejawat? Pernahkah guru setelah mengajar diberi komentar oleh guru lainnya? Bagaimana guru bisa bersikap terbuka terhadap rekan guru? Bagaimana menumbuhkan sikap kolaboratif di kalangan guru? Bagaimana menyerap kandungan-kandungan kearifan lokal untuk memupuk kesadaran 
kebersamaan para guru? Pertanyaanpertanyaan tersebut merupakan dasar dari formulasi model hipotetik lesson study berdasarkan kearifan lokal. Formulasi model tersebut terlihat dalam gambar di bawah ini:

1. UU No. 14 Pasal 1 ayat 1

2. Pengelolaan kelas jadi monopoli guru

3. Pembelajaran dilakukan tanpa perencanaan yang matang

4. Tidak ada umpan balik

5. Semangat kerjasama guru rendah

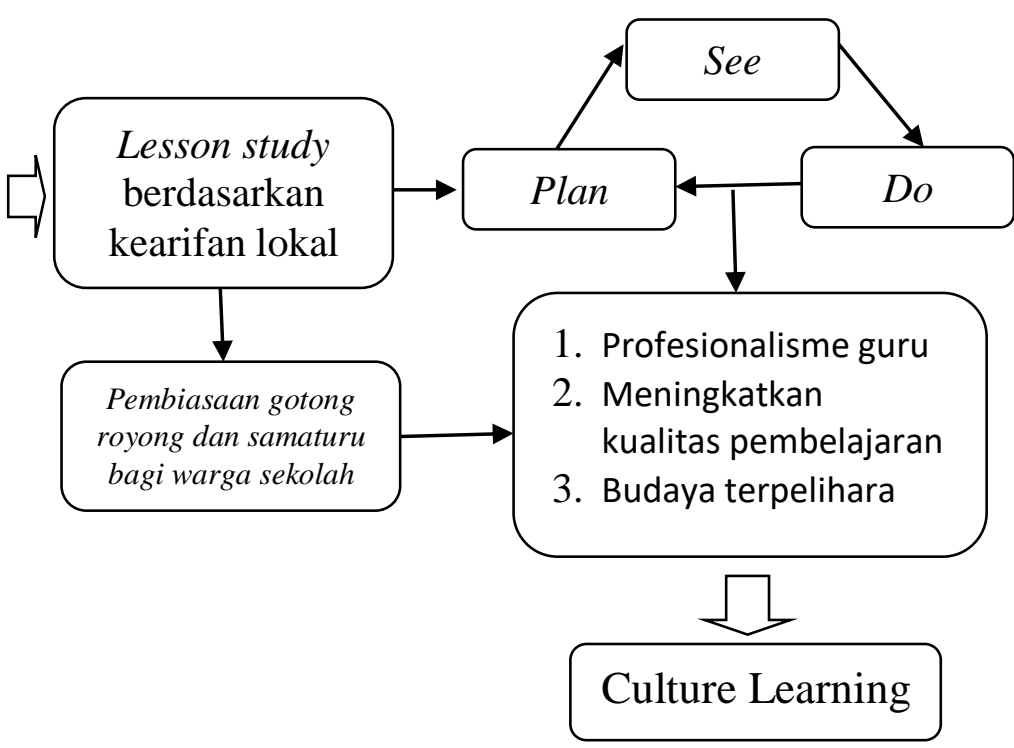

Tugas guru sebagaimana datang di sekolah, mereka hanya disebutkan pada pasal 1 ayat (1) UU No. memeriksa kelengkapan administrasi 14 tahun 2005 tentang Guru dan Dosen guru berupa dokumen renpel (rencana berfungsi untuk meningkatkan mutu pendidikan. Tetapi, proses pembelajaran yang terjadi di dalam kelas tidak ada yang tahu kecuali guru itu sendiri. Selama ini proses pembelajaran kurang mendapat perhatian dari orang tua dan pemerintah. Bahkan keberadaan pengawas dari Dinas Pendidikan belum berfungsi sebagai supervisor pembelajaran di kelas. Ketika pengawas pelajaran). Pengawas sangat jarang masuk kelas melakukan observasi terhadap pembelajaran dan tidak memberikan umpan balik kepada guru di sekolah. Banyak guru yang tidak pernah tahu dan tidak pernah paham tentang realitas mengajarnya karena tidak ada yang memberikan umpan balik.

Lesson study didahului dengan adanya kesepakatan dari para guru 
tentang tujuan bersama yang ingin ditingkatkan dalam kurun waktu jangka panjang dengan cakupan tujuan yang lebih luas (Sulaiman, dkk. 2011), misalnya tentang: pengembangan kemampuan akademik siswa, pengembangan kemampuan individual siswa, pemenuhan kebutuhan belajar siswa, pengembangan pembelajaran yang menyenangkan, mengembangkan kerajinan siswa dalam belajar, dan sebagainya. Melalui lesson Study guru dibiasakan untuk senantiasa merencanakan, melaksanakan, dan mengevaluasi pembelajaran yang dilaksanakannya. Sedangkan integrasi tradisi samaturu melalui "pembiasaan" warga sekolah (administrator, guru dan siswa) di lingkungan sekolah akan melahirkan kultur learning community (komunitas belajar). Lesson study bukanlah suatu strategi atau metode dalam pembelajaran, tetapi lesson study merupakan salah satu upaya pembinaan untuk meningkatkan proses pembelajaran yang dilakukan oleh sekelompok guru secara kolaboratif dan berkesinambungan, dalam merencanakan, melaksanakan, mengobservasi dan melaporkan hasil pembelajaran. Lesson Study bukan sebuah proyek sesaat, tetapi merupakan kegiatan terus menerus yang tiada henti dan merupakan sebuah upaya untuk mengaplikasikan prinsip-prinsip dalam Total Quality Management, yakni memperbaiki proses dan hasil pembelajaran siswa secara terus-menerus. Lesson Study merupakan kegiatan yang dapat mendorong terbentuknya sebuah komunitas belajar (learning society) yang secara konsisten dan sistematis melakukan perbaikan diri, baik pada tataran individual maupun manajerial. Ong, Lim \& Ghazali (2010) merumuskan lesson Study sebagai salah satu model pembinaan profesi pendidik melalui pengkajian pembelajaran secara kolaboratif dan berkelanjutan berlandaskan pada prinsip-psrinsip kolegalitas dan mutual learning untuk membangun komunitas belajar. Sementara itu, Lewis (2002b) menyebutkan bahwa: "lesson study is a simple idea. If you want to improve instruction, what could be more obvious than collaborating with fellow teachers to plan, observe, and reflect on lessons? While it may be a simple idea, lesson study is a complex process, supported by collaborative goal setting, careful data collection on student learning, and protocols that enable productive discussion of difficult issues".

Dalam pelaksanaannya, lesson study terdiri dari tiga tahapan yaitu: 
tahapan perencanaan, tahapan pelaksanaan, tahapan refleksi dan tindak lanjut (Teacher Institute, 2008). Pada akhirnya, lesson study adalah model pembinaan (pelatihan) profesi pendidik melalui pengkajian pembelajaran secara kolaboratif dan berkelanjutan berdasarkan prinsip prinsip kolegalitas. Lesson study akan bermanfaat untuk pengembangan profesionalisme guru. ketika profesionalisme guru telah tumbuh, maka mutual learning dan akan terbangun komunitas belajar di lingkungan sekolah.

\section{PENUTUP}

Samaturu adalah budaya Indonesia dan budaya lokal masyarakat tolaki di Sulawesi Tenggara. Budaya Samaturu dilakukan dengan asas kesadaran dan semangat untuk kebersamaan. Budaya Samaturu mengeratkan hubungan persaudaraan dan silaturahmi. Spirit Samaturu memupuk semangat kerja sama guruguru untuk refleksi hasil proses belajar dan menemukan solusi memperbaiki masalah pembelajaran. Budaya Samaturu mengajarkan kepada guru untuk berpartisipasi dalam kegiatan lesson study menurut kemampuan masingmasing; berdasarkan keikhlasan dan suka rela, tanpa pamrih, dan meyakini jika kerja atau usaha tersebut bermanfaat bagi kepentingan bersama. Pada akhirnya, mengekstraksi nilai Samaturu akan bermanfaat untuk menumbuhkan semangat kolaborasi guru-guru. Peneliti merekomendasikan kepada penelitipeneliti di masa depan yang fokus pada topik serupa untuk melakukan pengujian terhadap model hipotetik dibuat dengan menggunakan pendekatan kuantitatif.

\section{UCAPAN TERIMAKASIH}

Terimkasih kepada semua pihak yang telah membantu penulisan karya ilmiah ini.

\section{DAFTAR PUSTAKA}

Bleidorn, W., Kandler, C., \& Caspi, A. 2014. The behavioural genetics of personality development in adulthood-Classic, contemporary, and future trends. European Journal of Personality, 28, 244255.

Chassels, C., \& Melville, W. 2009. Collaborative, Reflective, and Iterative Japanese Lesson Study in an Initial. Teacher Education Program: Benefits and Challenges. Canadian Journal Education, 32(4), 734-763.

Dick, W., Carey, J.O. 2009. The systematic design of instruction. New Jersey: Pearson.

Fernandez, C., \& Yoshida, M. 2012. Lesson Study: A Japanese Approach To Improving 
Mathematics Teaching and Learning. Routledge.

Friedkin, Shelley. 2005. What is Lesson Study?.

http://www.lessonresearch.net/.

Hock, C. U., \& Sam, L. C. 2010. Disseminating and Popularising Lesson Study in Malaysia and Southeast Asia. APEID Hiroshima Seminar. Current Status and Issues on Lesson Study in Asia and the Pacific Regions, 1-9.

Leung K, \& Cohen, D. 2011. Allocentric versus idiocentric tendencies: convergent and discriminant validation. J. Res. Pers. 19:395415.

Lewis, C. 2002a. Nagoya Journal of Education and Human Development: Does Lesson study Have a Future in the United States? January No. 1:1-23.

Lewis, C. 2002b. Lesson study: The core of Japanese professional development. Paper presented at the American Educational Research Association Annual Meeting, New Orleans.

Miles, Matthew B., A. Michael Huberman, Johnny Saldana. 2014. Qualitative Data Analysis: A Methods Sourcebook. Thousand Oaks, CA: Sage.

Nasir. (2013). Pengembangan Pendidikan Karakter Berbasis Budaya Lokal di SMPN 2 Kendari. Di download dari:

http://eprints.ums.ac.id/26406/13/

Publikasi_Ilmiah.pdf.

Ngang, T. K., \& Sam, L. C. 2015.

Principal Support in Lesson

Study. Procedia - Social and

Behavioral Sciences, 205, 134139.

Ong, E. G., Lim, C. S., \& Ghazali, M. 2010. Examining the Changes in Novice and Experienced Mathematics Teachers'
Questioning Techniques through the Lesson Study Process. Journal of Science and Mathematics Education in Southeast Asia, 33(1), 86-109.

Perry, R., Lewis, C., Friedkin, S. and Baker, E. (2009). Teachers' Knowledge Development During Lesson Study: Impact of ToolkitSupported Lesson Study on Teachers' Knowledge of Mathematics for Teaching. Paper presented at AERA. March 24,2009, San Diego.

Setiartin, Titin. 2016. Pembentukan Mental dan Kepribadian Melalui Budaya Daerah (Kajian NilaiNilai Sastra Lisan Jawa Barat "Sawer Panganten"). Konferensi Nasional Bahasa dan Sastra III, http://s3pbi.fkip.uns.ac.id/wpcontent/uploads/2016/01/TitinSetiartin.pdf

Shakenova, Lyailya. 2017. The Theoretical Framework of Teacher Collaboration. Khazar Journal of Humanities and Social Sciences, Volume 20 № 22017 , 34-48.

Sulaiman, M., Ismail, Z. H., Aziz, A. A., \& Zaharim, A. 2011. Lesson Study: Assessing Pre-Service Teacher's Performance of Teaching Chemistry. Engineering Education (ICEED), Proceedings of the 3rd International Congress, 208-213.

Takahashi, Akihiko \& McDougal, Thomas. 2016. Collaborative lesson research: maximizing the impact of lesson study. ZDM Mathematics Education, 48:513526.

Teacher Institute. 2008. Implementasi Lesson Study: Program Pengembangan profesionalitas Pendidik dan Tenaga Kependidikan di Kabupaten Karawang, Kabupaten \& Kota 
Pasuruan, dan Kota Surabaya.

UPI dan Putera Sampoerna

Foundation.

Triandis, C. Harry \& Suh M. Eunkook. 2002. Cultural Influences On

Personality. Annu. Rev. Psychol, 2002. 53:133-60.

Triyanto, Itok Dwi Kurniawan. 2016. Improving Spirit Of Learning Through Lesson Study. Proceeding The 2nd International Conference On Teacher Training and Education Sebelas Maret University 577 Volume 2 Number 12016 ISSN: $25002-4124$.

Undang-Undang nomor 14 tahun 2005 tentang guru dan dosen.

Utami, W., Septi. 2009. Penerapan Pendidikan Karakter Melalui Kegiatan Kedisiplinan Siswa. Jurnal Pendidikan. Volume 04 Nomor 01 Tahun 2019 Halaman 63-66

Zubaedah, Siti. 2010. Lesson Study Sebagai Salah Satu Model Pengembangan Profesionalisme Guru. Conference: Pendidikan dan Pelatihan Nasional dengan Tema Peningkatan Profesionalisme Guru melalui Kegiatan Lesson Study, di Universitas Brawijaya Malang 